\title{
Descrição do macho de Apophorhynchus flavidus Williston e chave de identificação, baseada em machos, para espécies de Apophorhynchus Williston (Diptera, Ropalomeridae)
}

\author{
Rosaly Ale-Rocha ${ }^{1} \&$ Veracilda Ribeiro Alves ${ }^{1}$
}

${ }^{1}$ Coordenação de Pesquisa em Entomologia, Instituto Nacional de Pesquisas da Amazônia-INPA, Caixa Postal 478, 69011-970 Manaus-AM, Brasil. alerocha@inpa.gov.br; veraent@inpa.gov.br

\begin{abstract}
Description of male of Apophorhynchus flavidus Williston and identification key, based on males, for species of Apophorhynchus Williston (Diptera, Ropalomeridae). The male of Apophorhynchus flavidus is described for the first time. An identification key for species of Apophorhynchus Williston based on males is presented.

KEYWORDS. Apophorhynchus; identification key; taxonomy.

RESUMO. Descrição do macho de Apophorhynchus flavidus Williston e chave de identificação, baseada em machos, para espécies de Apophorhynchus Williston (Diptera, Ropalomeridae). O macho de Apophorhynchus flavidus é descrito pela primeira vez. Uma chave de identificação para espécies de Apophorhynchus Williston, baseada em machos, é apresentada.
\end{abstract}

PALAVRAS-CHAVE. Apophorhynchus; chave de identificação; taxonomia.

Apophorhynchus Williston, 1895 é um gênero de moscas castanhas, medindo de 7,9 a $10 \mathrm{~mm}$, com fronte ampla e pouco côncava, cerdas ocelar e pós-ocelar ausentes, face com tubérculo central pontiagudo, arista plumosa, escutelo sem cerdas de revestimento, geralmente com 1 par apical e 1 par marginal de cerdas desenvolvidas e pernas com fêmures moderadamente alargados. Inclui três espécies conhecidas: A. flavidus Williston, 1895 (Brasil - Mato Grosso; Bolívia), A. amazonensis Prado, 1966 (Brasil - Amazonas e Rondônia; Peru) e A. brevipennis Marques-Costa e Ale-Rocha, 2005 (Brasil Amazonas). Foi revisado recentemente por Marques-Costa \& Ale-Rocha (2005) e até o presente não se conhecia o macho da espécie-tipo do gênero, A. flavidus. Neste trabalho descrevese o macho de A. flavidus e uma chave de identificação para espécies de Apophorhynchus, baseada em machos, é fornecida.

\section{MATERIALE MÉTODOS}

Foram examinados 12 espécimes, 5 machos e 7 fêmeas, de A. flavidus montados em alfinetes. O material foi coletado pela segunda autora na Reserva Particular do Patrimônio Natural do Serviço Social do Comércio (RPPN SESC Pantanal), município de Poconé no Estado do Mato Grosso, onde também se localiza a localidade- tipo da espécie, a Chapada dos Guimarães.

O abdome dos machos foi desprendido, para análise das estruturas da terminália. A terminália foi aquecida em ácido lático $85 \%$ por 30 minutos, transferida para microtubos de plástico $(4 \times 10 \mathrm{~mm})$ com glicerina, e afixados no alfinete do espécime. A terminologia empregada segue o trabalho de
McAlpine (1981). O material está depositado na Coleção de Invertebrados do INPA, Instituto Nacional de Pesquisas da Amazônia, Manaus.

Apophorhynchus flavidus Williston, 1895

(Figs. 1-5)

Apophorhynchus flavidus Williston, 1895: 184, 186-187 (chave, descrição da fêmea); Prado, 1966: 248, 249-251 (chave, redescrição, ilustrações, distr. geográfica); Steyskal, 1967: 1 (catálogo); Marques-Costa \& Ale-Rocha, 2005 (chave, redescrição, ilustrações, distr. geográfica).

Espécie revisada por Marques-Costa \& Ale-Rocha (2005) com desenhos da terminália feminina e asa. Fêmeas e machos foram associados através dos caracteres gerais. $\mathrm{O}$ macho foi estudado e descrito a seguir.

Macho. Comprimento do corpo: 8,0-8,2 mm ( $\mathrm{n}=3)$. Cabeça: fronte alaranjada, mais escura na metade basal, com triângulo central e margem ocular com polinosidade prateada; antena alaranjada; arista amarela no $1 / 4$ basal, e acastanhada no restante; clípeo amarelado, brilhante; tubérculo facial castanho brilhante; região abaixo da antena com pruína prateada esparsa; face castanho-clara, sub-brilhante, com pequena mancha lateral amarela a amarelo-escura; genas com cerdas amarelo-claras; palpos com cerdas castanhas dorsais e amarelas ventrais. Tórax: escuto castanho com uma faixa acrostical estreita e curta, restrita à região pré-sutural e uma faixa dorsocentral, 2 vezes mais larga que a acrostical, estendendo-se até o ápice do escutelo, de polinosidade prateada esparsa; uma faixa lateral 


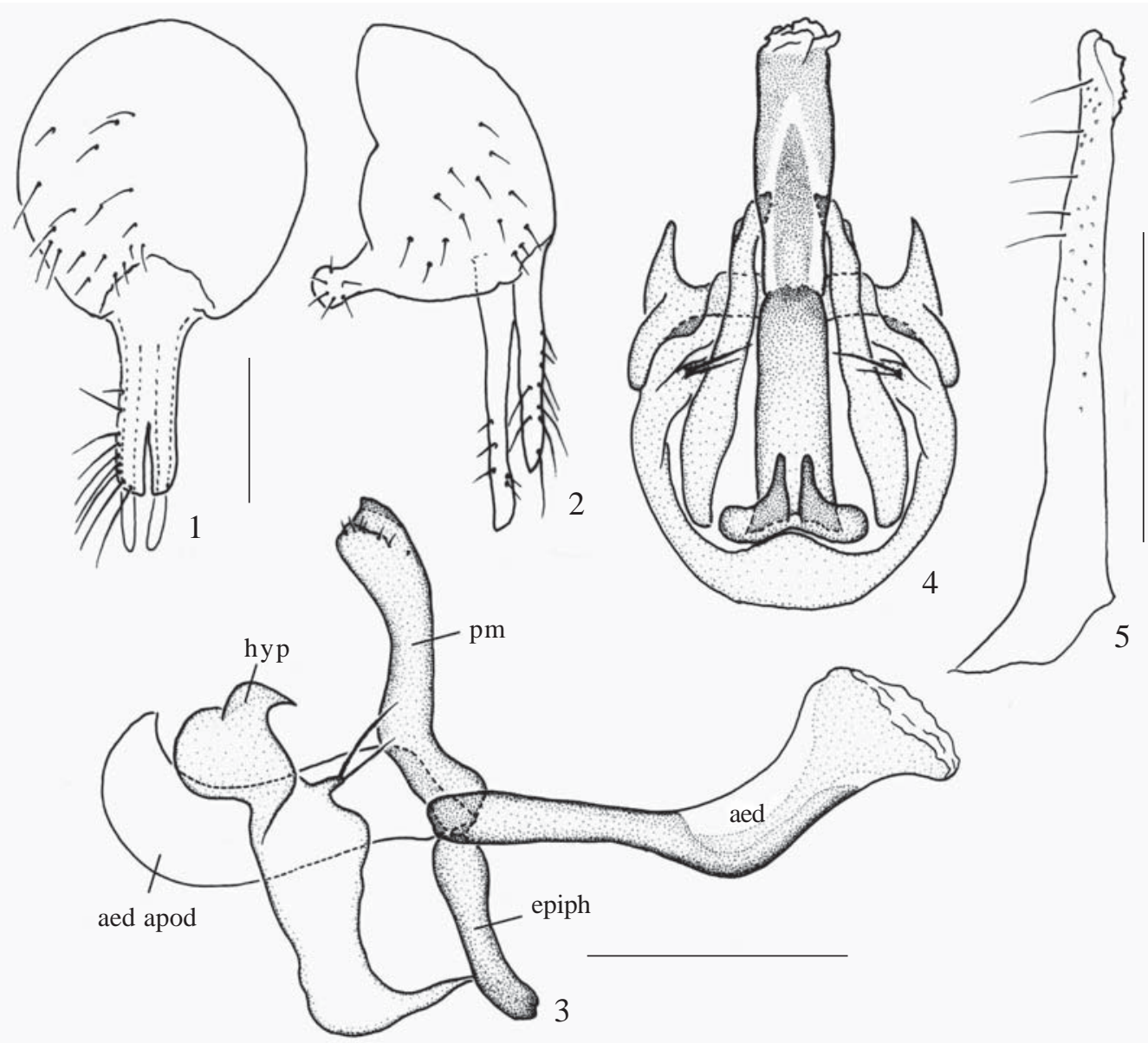

Figs. 1-5. Apophorhynchus flavidus (macho):1, 2, terminália (vistas ventral e lateral, mesma escala); 3, 4, terminália interna (vistas lateral e ventral, mesma escala); 5, surstilo esquerdo (vista lateral). Escala = 0,5 $\mathrm{mm}$. Abreviaturas:aed = edeago, aed apod = apódema do edeago; epiph = epifalo; hyp = hipândrio; $\mathrm{pm}=$ parâmero.

de polinosidade dourada clara e mais densa, estendendo-se do lobo pós-pronotal até o calo pós-alar; cerdas torácicas características do gênero; pleura castanha, fosca. Asa: uniformemente amarelada; veias castanhas. Pernas: coxa anterior amarelada; coxas média e posterior castanhas; trocânteres anterior e médio amarelos; fêmures anterior e médio amarelos com a face posterior amarelo-escura; fêmur posterior amarelo com as faces anterior e ântero-ventral castanhas e mancha longitudinal oval-alongada, castanho-escura brilhante no $1 / 4$ distal da face anterior; tíbias anterior e média amarelas com mancha castanha apical nas faces anterior e posterior e anel basal castanho, largo; tíbia posterior com anel sub-basal e apical castanhos, estreitos; trocânter posterior castanho com cerdas ventrais curtas, pretas e densas; fêmur anterior com 45 cerdas espiniformes na $1 / 2$ apical da face posterior e 3-4 cerdas espiniformes na $1 / 2$ apical da face ântero-ventral; fêmur médio com 6-9 cerdas espiniformes ântero-ventrais e 5-6 cerdas póstero-ventrais; fêmur posterior alargado com 8-10 cerdas curtas, espiniformes, ântero-ventrais e 5-6 póstero-ventrais. Abdome: com densa polinosidade dorsal castanha e prateada nas margens laterais dos tergitos 1-6; tergitos 7 e 8 castanhos, brilhantes, sem polinosidade; esternitos com polinosidade prateada esparsa. Terminália: expansão póstero-lateral do epândrio levemente arredondada (Fig. 2); cerco longo (Figs. 1, 2); surstilo com margem lateral serrilhada apicalmente (Fig. 5); parâmero alongado, ultrapassando a metade do comprimento do edeago (Fig. 3); edeago curto, robusto com ápice membranoso (Figs. 3, 4); 2 cerdas, uma longa e forte, outra curta e delgada, no tubérculo do gonópodo.

Distribuição. Brasil (Mato Grosso) e Bolívia.

Material examinado. BRASIL, MT [Mato Grosso], Poconé, RPPN SESC Pantanal, 16.vii.2004, base, Arm. Van Someren -Rydan, R. Alves, 2 machos (INPA); 16.viii.2004, mata, 2 machos (INPA); 19.viii.2004, base, 1 macho, 1 fêmea (INPA); 20.viii.2004, 1 fêmea (INPA); 16.ix.2004, 2 fêmeas (INPA); 17.ix.2004, 3 fêmeas (INPA).

Discussão. O exame do macho de A. flavidus mostra que a terminália masculina aparentemente não fornece caracteres conspícuos para separação das espécies nesse gênero visto que a terminália de $A$. flavidus assemelha-se em certos aspectos à de $A$. amazonensis e A. brevipenis. O edeago é curto como em $A$. brevipenis diferindo de A. amazonensis onde é longo, mas o surstilo tem a margem lateral serrilhada apicalmente como em $A$. amazonensis, diferindo de $A$. 
brevipenis onde o surstilo tem a margem lateral lisa apicalmente. Outras estruturas como cercos, parâmeros, epândrio e hipândrio assemelham-se nas três espécies, embora o parâmero em A. flavidus seja um pouco mais longo que nas demais espécies. Os caracteres definitivos que separam as três espécies mais facilmente são aqueles ligados à coloração e outros caracteres externos, os quais são utilizados na chave.

Chave para espécies de Apophorhynchus Williston (machos)

1- Pernas predominantemente castanhas, tíbia posterior castanho-escura a preta; tergito 1 com cerdas basais dorso-laterais delgadas, castanhas, esparsas; fêmur posterior cerca de 3 vezes mais longo que largo A. brevipernnis

Pernas predominantemente amarelas com manchas castanhas, tíbia posterior amarela com anel sub-basal e apical castanhos; cerdas basais do tergito 1 e largura do fêmur posterior variável 2

2 - Base do tergito 1 com cerdas laterais pretas e fortes e dorsolaterais castanho-claras, delgadas; fêmur posterior fortemente dilatado, cerca de 2,5 vezes mais longo que largo A. amazonensis
Base do tergito 1 com cerdas delgadas, amarelo-douradas, delgadas, esparsas; fêmur posterior mais delgado, cerca de 3 vezes mais longo que largo A. flavidus

Agradecimentos. A Coordenação de Aperfeiçoamento de Pessoal de Nível Superior (CAPES) pela bolsa de mestrado concedida à segunda autora.

\section{REFERÊNCIAS}

Marques-Costa, A. P. \& R. Ale-Rocha. 2005. Revisão do gênero neotropical Apophorhynchus Williston (Diptera, Ropalomeridae). Revista Brasileira de Entomologia 49: 512-521.

McAlpine, J. F. 1981. Morphology and terminology - Adults, p. 9-63. In: J. F. McAlpine (coord.). Manual of Nearctic Diptera. Vol. 1. Research Branch Agricuklture Canada Monograph n 27.

Prado, A. P. 1966. Segunda contribuição ao conhecimento da família Rhopalomeridae (Diptera, Acalyptratae). Studia Entomologica 8 [1965]: 209-268.

Steyskal, G. C. 1967. Family Ropalomeridae, p. 1-7. In: A catalogue of the Diptera of the Americas south of the United States. São Paulo, Departamento de Zoologia, Secretaria de Agricultura, v. 60 .

Williston, S. W. 1895. On the Rhopalomeridae. Psyche 7: 183-187.

Recebido em 04/05/2006; aceito em 28/08/2006 